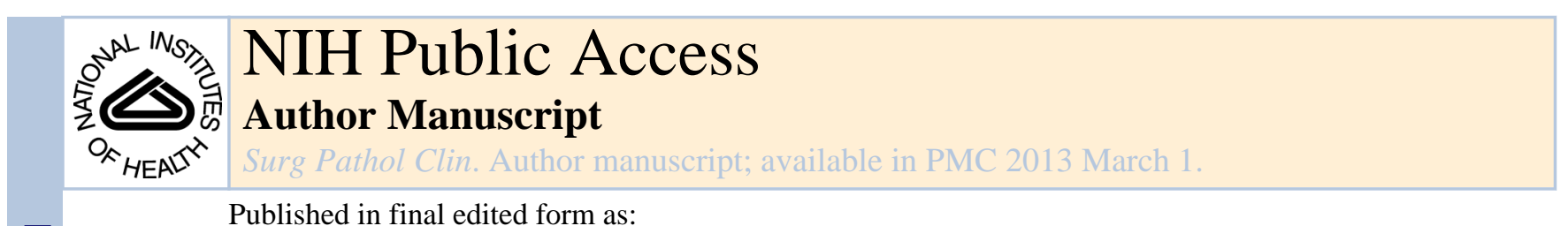

Published in final edited form as:

Surg Pathol Clin. 2012 March 1; 5(1): 301-318. doi:10.1016/j.path.2011.07.015.

\title{
Treatment of Bone Tumors
}

\author{
Rajiv Rajani, MD and C. Parker Gibbs, MD \\ University of Florida Department of Orthopaedics and Rehabilitative Medicine, Division of \\ Oncology, Gainesville, FL
}

\section{Synopsis}

In this article, the authors summarize the state of the art and future potential in the management of Osteosarcoma, Ewing's sarcoma, and Chondrosarcoma. They cover systemic therapy, surgical therapy, and radiotherapy, along with targeted therapies to inhibit signal transduction pathways. They discuss staging and the role of imaging evaluation to provide an overview of bone tumor treatment. Images presenting pathologic-radiologic correlations are included.

Malignant bone tumors are rare neoplasms that cause significant morbidity and mortality. Despite advances in both surgical and medical oncology, few significant positive changes in function or survival have occurred for patients with these diseases over the past 30 years.

\section{OSTEOSARCOMA}

\section{Overview}

Osteosarcoma is a highly malignant mesenchymal tumor of bone in which the malignant cells produce osteoid. It is the most common primary, non-hematologic bone malignancy in children, occurring most frequently in patients between the ages of 10 and $25^{1}$. Prior to the advent of multi-agent chemotherapy, amputation provided a long-term survival rate of about $20 \%$. The use of multi-agent chemotherapy combined with aggressive surgery has improved the long-term survival in these patients to approximately $60 \% .{ }^{2}$ Interestingly, survival of patients treated with chemotherapy alone is only $20 \%,{ }^{3}$ suggesting that populations of tumor cells in a large percentage of osteosarcomas are highly resistant to chemotherapy. Despite intensive efforts in both surgical and medical management, the survival rate has not improved over the last 30 years and fully $40 \%$ of osteosarcoma patients die of their disease.

Osteosarcoma can arise in any bone, but occurs primarily in the juxta-epiphyseal regions of rapidly growing long bones. The histopathologic appearance of high-grade intramedullary osteosarcoma is one of malignant spindle cells producing osteoid and immature bone.(Fig 1D and 1E) The bone structure is disorganized and can appear as a fine lacey trabecular pattern or as irregular clumps of osteoid, distinctly unlike normal bone formation. Classic osteosarcoma may also appear to be predominantly fibrous or chondroid with only small areas of osteoid formation. ${ }^{1}$ Grossly, osteosarcoma begins as a process destructive of medullary bone that progresses to destroy cortical bone, often with a large associated soft

\footnotetext{
(C) 2011 Elsevier Inc. All rights reserved.

Dr. Gibbs (Corresponding Author), gibbscp@ ortho.ufl.edu, PO Box 112727, Gainesville, FL 32611. Dr. Rajani, rajanr@ortho.ufl.edu, PO Box 112727, Gainesville, FL 32611

Publisher's Disclaimer: This is a PDF file of an unedited manuscript that has been accepted for publication. As a service to our customers we are providing this early version of the manuscript. The manuscript will undergo copyediting, typesetting, and review of the resulting proof before it is published in its final citable form. Please note that during the production process errors may be discovered which could affect the content, and all legal disclaimers that apply to the journal pertain.

The authors have no conflicts of interest.
} 
tissue component. (Fig 1A) The natural history of osteosarcoma is one of relentless local progression with loss of the function of the affected extremity and distant metastasis, most often to the lung. ${ }^{2,4}$ A small percentage of patients develop bone metastases which are almost always fatal..$^{5}$

\section{Etiology}

Cytogenetic evaluation has revealed numerous complex chromosomal abnormalities that vary both within and between individual tumors in osteosarcoma. Different from other sarcomas, such as Ewing's sarcoma, synovial sarcoma and alveolar rhabdomyosarcoma, osteosarcoma has not been associated with a specific recurrent chromosomal rearrangement. ${ }^{6}$ Molecular analyses have revealed a variety of genetic alterations in osteosarcoma, including inactivation of p53 and retinoblastoma (Rb) tumor suppressor genes and overexpression of oncogenes such as MDM2. ${ }^{7}$ For example, alterations of the RB1 gene have been shown in up to $70 \%$ of reported cases, and loss of heterozygosity for RB1 has been shown to be a marker of poor prognosis. Patients with retinoblastoma develop osteosarcoma at a rate 500 times the general population. ${ }^{8}$

Osteosarcoma is the second most common malignancy associated with Li-Fraumeni syndrome characterized by p53 mutations at chromosome $17 \mathrm{p} 13$ and the development of numerous and varied cancers. ${ }^{9}$ Although this information has provided insight into aspects of the molecular dysregulation of osteosarcoma and its heterogeneous nature, to date these types of studies have been of limited value in establishing the molecular determinants of tumorigenesis or in the development of effective therapies. ${ }^{10}$ In recognition of this, recently some authors have postulated a role for tumor initiating cells in the pathogenesis of osteosarcoma. The existence of these so called "cancer stem cells" was first suggested by the observation that osteosarcoma cells grown in media developed to isolate neural stem cells expressed primitive transcription factors normally restricted to embryonic stem cells ${ }^{11}$. Following this, Wu et al noted that sarcoma cells isolated based on the ability to exclude Hoechst dye (side population) appeared to exhibit increased tumorigenic potential relative to those cells that could not ${ }^{12}$. Most recently, Levings et al demonstrated the ability to prospectively identify a highly tumorigenic subpopulation of cells within an individual osteosarcoma by its ability to transcriptionally activate an Oct-4 promoter driven GFP reporter. Their data suggested that the osteosarcoma initiating cell might be regulated at an epigenetic level ${ }^{1313}$. Together, these recent reports offer further insight into the origin of this aggressive malignancy.

\section{Imaging}

Appropriate local and distant imaging continues to be critical for the accurate staging of osteosarcoma patients. The diagnosis is most often strongly suggested by plain radiography. Radiographs of the entire bone are obtained and classically demonstrate a metaphyseal lesion destructive of both cortical and medullary bone with an ossified extra-osseous soft tissue mass.(Fig 1 A) Over 50\% of osteosarcomas occur about the knee. Although plain radiographs are almost diagnostic, magnetic resonance imaging (MRI) is the gold standard for determining the anatomic extent of the tumor and pre-operative planning. An MRI of the entire involved bone is used to determine both the intra and extra-osseous extent of the tumor. MRI reveals the proximity of vital neuro-vascular structures, as well as the presence of skip metastases and intra-articular involvement.(Fig 1B and 1C) Technetium bone scans are used to detect both skip and distant bone metastases ${ }^{14}$. Computerized tomography (CT) scans are used for determining the presence of pulmonary metastases and less so for the assessment of the primary tumor. The vast majority of metastases from osteosarcoma occur to the lungs. 
Positron emission tomography (PET) is currently being evaluated as an imaging modality in osteosarcoma. The potential advantage of PET scanning is that it may be able to demonstrate tumor viability and response to chemotherapy and therefore help guide therapy. One study has reported that high standardized uptake values (SUV) either before or after chemotherapy portend a worse prognosis ${ }^{15}$. Although the role of PET scans in the staging of osteosarcomas in unknown at present, as more data is collected, the benefit of PET scans may become elucidated.

\section{Surgical Management}

In most cases of osteosarcoma, the treatment protocol includes surgical resection of the primary tumor and any bony metastasis. The surgical margin, reconstruction, and adjuvant therapy plan are further delineated by the subtype of osteosarcoma. These include juxtacortical, intramedullary, and periosteal subtypes. Each has a different local recurrence, metastatic, and survival rate.

High-grade intramedullary osteosarcoma is the prototypical bone sarcoma. It usually presents with not only cancellous and cortical bone destruction but significant soft tissue extension. Therapy normally consists of neoadjuvant chemotherapy followed by wide surgical resection and subsequent adjuvant chemotherapy. The resulting skeletal defect is most commonly managed by reconstruction with modular metallic prostheses, allogeneic bone grafts or a combination of both. Parosteal osteosarcoma is typically a low-grade lesion that occurs on the posterior aspect of the distal femur, although it can occur on the cortical surface of any bone. The mainstay of treatment is wide surgical excision. Chemotherapy can be utilized in patients with dedifferentiated high-grade lesions. Radiographically, it appears as a lobular ossified mass with well-marginated borders pasted onto the surface of the bone. Histologically, it has the appearance of a well-differentiated spindle cell sarcoma with minimal atypia. This tumor typically arises from the periosteum and survival rates are greater than $80 \%$ at 5 years. 16

Low-grade intramedullary osteosarcoma accounts for approximately 1 to $2 \%$ of osteosarcomas and also is generally a low-grade lesion. It occurs in the metaphysis and diaphysis of long bones. Radiographically, it appears as an intramedullary lesion with variable density and poorly defined margins. It may be radiodense, lucent, or mixed. Oftentimes, it is mistaken for a benign lesion. Histologically, it is similar to parosteal osteosarcoma in that it is low grade and predominantly fibrous. Overall, the cellularity is low and can be confused with fibrous dysplasia. Management of most lesions is surgical with wide excision and reconstruction, depending on the location and extent of the lesion. Chemotherapy is not commonly used. Schwab et al reviewed 59 patients with these two diseases and showed that the rates of local recurrence, dedifferentiation, distant metastases, and survival were the same. Although the physical location of these lesions is different (endosteal versus parosteal), the authors felt they represented similar entities and should be treated similarly. ${ }^{17}$

Periosteal osteosarcoma often presents as another surface variant of osteosarcoma with erosion of the cortex usually apparent on plain radiographs. Histologically, these tumors are largely chondroblastic with some areas of osteoid formation. There is a high level of variability with most lesions being low-grade but with a greater likelihood of high-grade lesions than parosteal osteosarcomas. Treatment still consists of wide surgical resection with chemotherapy reserved for high-grade and metastatic lesions. 


\section{Systemic Therapy}

The most dramatic improvement in survival for osteosarcoma occurred in the late 1970s and early 1980s with the development of multi-agent chemotherapy. Prior to the use of chemotherapy, amputation alone provided only a $20 \%$ chance of survival. Some early benefit was seen with single agent doxorubicin. This early success was improved with the addition of methotrexate and reported survivals of up to $60 \% .{ }^{18,19}$ As limb salvage surgery became more common with relatively effective chemotherapeutic agents, the drugs were given most often in a neo-adjuvant manner. This provided the theoretic benefits of killing microscopic metastatic disease and facilitating surgical resection by decreasing the tumor in the reactive zone about the primary tumor. However, in reality, the practice was started to provide surgeons the 6 to 8 weeks required to fabricate custom prostheses for these patients. Today, in the age of modular readily available prostheses, most surgeons and oncologists still prefer neo-adjuvant therapy although no survival data exists supporting its use over that in the adjuvant setting.

Current chemotherapy regimens include doxorubicin, high dose methotrexate, cisplatin and sometimes ifosfamide. This multi-drug approach yields survival rates of approximately $70 \%$ in those patients with no evidence of metastasis at diagnosis. ${ }^{20}$ However, those patients presenting with metastases, enjoy only a $20 \%$ survival rate. It has been shown that those patients who exhibit greater than $90 \%$ necrosis of their primary tumor upon resection after neo-adjuvant therapy have a significant survival advantage. ${ }^{21}$ Although this would suggest changing agents in those patients who responded poorly to induction therapy, unfortunately no studies to date have demonstrated this to be of benefit. To further study this, the European and American Osteosarcoma Study Group 1 in a collaborative effort with the Children's Oncology Group has an ongoing multi-national study to determine the effectiveness of adding ifosfamide and etoposide after resection in poor responders.

\section{New Directions}

Agents that inhibit signal transduction pathways are among the few promising therapeutics being developed in sarcoma. The most studied in osteosarcoma are those that inhibit mammalian target of rapamycin (mTOR). mTOR, a member of the P13 kinase family, is a serine/threonine kinase that phosphorylates various downstream targets impacting cellular proliferation and mRNA translation among other functions. It is a critical component of the cell cycle progression from G1 to S phase. Altered mTOR signaling has been demonstrated in various malignancies and has been linked to a worse prognosis in osteosarcoma. ${ }^{22}$ Direct inhibition of mTOR with Rapamycin or its analogs has shown promise in vitro and in vivo. In fact, in one phase II trial, partial response or stability was demonstrated in $30 \%$ of patients treated with AP23573, an analogue of rapamycin. ${ }^{23}$

Current data suggest that the benefit of the mTOR inhibitors will largely be disease stabilization and that inroads toward increased survival will require combination therapy. ${ }^{24}$ Along these lines, their efficacy appears to be potentiated in vitro by the addition of zolendronate sodium, a commonly used bisphosphonate. ${ }^{25}$

Trans-membrane tyrosine kinase inhibitors such as imatinib have been a popular and sometimes effective target for novel therapies in a number of malignancies ${ }^{26}$. Their surface location and effect on downstream signal transduction cascades make them particularly attractive when designing targeted therapies. The insulin-like growth factor receptors have been extensively studied in osteosarcoma. IGF-1, 2 and 3 have all been found to be overexpressed in sarcomas ${ }^{27}$. One of the normal functions of IGF-1 is the regulation of longitudinal skeletal growth ${ }^{28}$. Thus dysregulation of IGF-1 and its receptor might be involved in osteosarcomagenesis ${ }^{29}$. The IGF-1 receptor (IGF-1 R) dimerically functions by 
binding both IGF-1 and IGF-2 affecting intracellular signaling of phosphatidylinositol 3' kinase (P13K) and mitogen activated protein kinase (MAPK). The developments of monoclonal antibodies to IGF-1 R have met with some pre-clinical success. In animal models with osteosarcoma xenografts, an antibody alone induced complete responses in two tumors ${ }^{30}$. Rapamycin in combination with a different anti-IGF-R antibody induced reduction of xenografts in three of four animals ${ }^{31}$. Clinical trials of monoclonal antibodies are ongoing. Unfortunately, the development of small molecule inhibitors to IGF-R 1 has been limited by the toxicity of these agents.

Muramyl tripeptide phosphatidylethanolamine (MTP-PE) is a non specific immune modulator that is a synthetic analogue of bacterial cell wall components. It is delivered encapsulated in liposomes, facilitating delivery to lung tissue where micrometastases exist. MTP-PE is believed to activate macrophages and monocytes against nearby tumor cells. MTP-PE has been shown to have a positive impact on survival when given in combination with standard chemotherapy in non-metastatic patients ${ }^{32}$. Although not as clear, its potential role in the treatment of patients who present with metastases is encouraging ${ }^{33}$.

\section{CHONDROSARCOMA}

\section{Overview}

Chondrosarcoma is a malignant mesenchymal tumor characterized by variously

differentiated cells producing chondroid matrix. Unlike Osteosarcoma and Ewing's sarcoma, it is usually a malignancy of adulthood with most cases occurring in patients over age 40 years ${ }^{1}$. Primary Chondrosarcomas are neoplasms that arise de novo from pre-existing normal bone. Secondary chondrosarcomas most often arise in the setting of an underlying pre-existing benign cartilaginous tumor such as enchondromas, multiple enchondromatosis, and multiple hereditary exostoses. However, they can also occur in conditions such as Paget's disease, fibrous dysplasia, irradiated bone, chondroblastoma, and although extremely rare, unicameral bone cysts and synovial chondromatosis.

Anatomically, the majority of cases occur in the pelvis, hip girdle, and shoulder girdle. The anatomic depth of these lesions often leads to a late diagnosis, potentially leading to poorer prognoses ${ }^{34}$. Most frequently the presenting symptom is pain referable directly to the site of the lesion. Often, a palpable mass can be appreciated to be growing while causing an external pressure effect leading to pain. Neurovascular compromise is uncommon.

The histopathologic appearance of cartilaginous tumors exhibit a continuum from well differentiated hyaline like hypocellular chondroid lesions with little or no mitotic activity to high-grade pleomorphic chondrosarcomas that may have very little chondroid at all. The prevailing appearance, however, is one of malignant spindle cells producing chondroid matrix. Grade I chondrosarcomas have little to no cellular atypia with an abundance of hyaline cartilage. (Fig 2D and 2E) Encasement of trabecular bone by the cartilage matrix can help to differentiate benign from low grade cartilage malignancy. Grade II chondrosarcomas have few mitoses, increased cellularity and may have mild cellular atypia. Grade III chondrosarcomas contain numerous mitotic figures and a myxoid cartilaginous matrix along with numerous atypical malignant spindle cells. The most highly malignant is dedifferentiated chondrosarcoma, characterized by the classic finding of low or intermediate grade cartilage tissue juxtaposed to a high grade spindle cell neoplasm. Grossly, high-grade central chondrosarcomas usually demonstrate significant cortical destruction and a soft tissue mass. In secondary tumors one can often appreciate the pre-existing lesion such as an osteochondroma or enchondroma. ${ }^{35}$ 
The natural progression of chondrosarcomas is generally slow, local growth with subsequent distant metastasis, most commonly to the lung. Five-year survival rates vary significantly based on size and histologic grade. Low-grade lesions have greater than $90 \%$ survival at 5 years while high-grade dedifferentiated chondrosarcomas have less than $20 \%$ survival in the same time frame. ${ }^{1}$ Distant metastasis at diagnosis, as with all sarcomas, portends a worse prognosis. ${ }^{36}$

\section{Etiology}

Hedgehog signaling has been implicated in the development of both benign and malignant cartilage lesions. Experiments blocking hedgehog signaling both in vitro and in vivo have shown decreased growth of chondrosarcoma ${ }^{37}$. p53 and RB alterations appear to be more correlated with high grade chondrosarcomas with approximately $96 \%$ having involvement of one or the other. ${ }^{38}$ In support of this, amplifications of $12 \mathrm{q} 13$ and loss of $9 \mathrm{p} 21$ both associated with p53 pathways, are seen consistently in chondrosarcoma ${ }^{39}$ Loss of INK4, which inhibits the cell cycle by causing arrest at G1, has also been associated with increasing histologic grade. ${ }^{40} \mathrm{CDK} 4$ has also been implicated as a driver of chondrosarcomagenesis and its knockdown by short hairpin RNAs have resulted in decreased colony formation in culture. ${ }^{38}$ Some have suggested an epigenetic component to the pathogenesis of chondrosarcoma. This has been supported by the demonstration of differentiation induction by histone deacetylase inhibitors in vitro. ${ }^{41,42}$ Further work looking at differences between benign cartilage, and the progression of malignant cartilage from low to high grade may yield even more clues as to the origin of this group of tumors.

\section{Imaging}

Plain radiographs in orthogonal planes are the initial radiologic study of choice. Primary chondrosarcomas appear as destructive lesions of bone often containing punctate calcification (Fig 2 A). The zone between the tumor and normal bone is often ill defined. The radiographic hallmarks of a malignant cartilage tumor include endosteal scalloping, frank cortical destruction, periosteal new bone, cortical thickening, and often soft tissue extension. In the setting of a pre-existing enchondroma, new areas of radiolucency may become apparent. ${ }^{43}$

Magnetic resonance imaging and computed tomography (CT) have been shown to have greater sensitivity when differentiating chondrosarcomas from enchondromas. ${ }^{44}$ Soft tissue and intramedullary extent can be measured for planned surgical resection (Fig 2C). In lesions arising from osteochondromas, the size of the cartilage cap, the determinant of malignancy can be measured.

Computed tomography also can be utilized to distinguish between benign and malignant lesions. Specifically, CT is recommended in the pelvis and other flat bones to distinguish the pattern of bone destruction, extent of mineralization and cartilage thickness (Fig 2B). CT is also used during staging to evaluate for the presence of pulmonary metastases.

The role of PET scanning in chondrosarcoma is evolving. Small case series have demonstrated some utility of PET in differentiating benign from malignant cartilaginous lesions when correlated with pathology. ${ }^{45}$ Others have suggested that PET can be used to predict histologic grade and outcomes in patients with chondrosarcoma. ${ }^{46}$ However, it should be noted that the accuracy of histopathology in determining the malignancy of low grade cartilage lesions is not high, therefore using it as a standard may not be appropriate. 


\section{Radiation Therapy}

Radiotherapy traditionally has not been useful for local or distant control of chondrosarcoma. It is relatively resistant to radiation and chemotherapy because of its low oxygen tension, low vascularity and relatively low rate of cell division ${ }^{47}$. Dosages of greater than $70 \mathrm{~Gy}$ are required and even at this dose, recurrence is common. Surrounding joints, neurovascular and viscus structures are at risk for adhesion, fibrosis, and necrosis. Proton beam therapy has been found to be beneficial in the setting of incompletely resected tumors around the skull base and spine and has been utilized with reasonable outcomes in unresectable tumors. ${ }^{48}$

\section{Systemic Therapy}

Similar to radiotherapy, chemotherapy is generally not effective in chondrosarcomas. In addition to prolonged doubling time and limited vascularity it has been suggested that the multidrug-resistance 1 gene (MDR-1) P-glycoprotein may play a role in chemotherapy resistance ${ }^{49,50}$ For conventional chondrosarcoma, current recommendations do not include use of adjuvant or neo-adjuvant chemotherapy.

In the specific setting of dedifferentiated chondrosarcomas containing a high-grade spindle cell component, some suggested efficacy for chemotherapeutic agents. Mitchell et al showed a small improvement in 22 patients but with median survival of only nine months and only $18 \%$ alive at 5 years ${ }^{51}$. Dickey et al, looking at 45 patients, showed poor results with median survival of 7.5 months and a 5 -year survival of only $7.1 \% .52$ Similarly, in a large multiinstitutional European study of 337 patients, no benefit of chemotherapy could be demonstrated. ${ }^{53}$ Clearly, better therapies need to be elucidated.

\section{Future Strategies}

Unlike Osteosarcoma and Ewing's sarcoma, currently there are no proven effective adjuvant therapies for chondrosarcoma, although early experimental results suggest possiblilities. One such group of agents is those that inhibit heat shock protein 90 (HSP 90). HSP 90 is a chaperone that ensures proper folding of attendant proteins such as the oncogenic proteins, BRAF, ERBB2, and CDK4 ${ }^{54,55}$. Agents that inhibit HSP 90 function then allow the depletion of the attendant oncoproteins and are thus attractive as anti-cancer drugs ${ }^{56}$.

Recent phase I work has shown stable disease in a small number of sarcomas, including a single chondrosarcoma, when patients were treated with the HSP 90 inhibitor, 17-DMAG. ${ }^{57}$ Oncostatin, a pro-apoptotic, cytostatic cytokine shown to have some efficacy against osteosarcoma cells has recently been evaluated in chondrosarcoma. ${ }^{58}$ The investigators noted that Oncostatin blocked cell cycle progression in four of five human cell lines examined and induced differentiation as measured by an increased Cbfa1/SOX 9 ratio, induced expression of Collagen 10, matrix metalloproteinase 13 (MMP13) and RANKL. They proposed the effect to be mediated by the JAK/STAT signaling pathway. Because of severe inflammatory side effects when given systemically, the authors noted that the delivery of Oncostatin would likely have to be injected directly into a patient's tumor, perhaps limiting its usefulness in the typically large tumors seen in human chondrosarcoma.

Perhaps one of the more promising agents is recombinant human apoptosis ligand 2/tumor necrosis factor-related apoptosis-inducing ligand (Apo2L/TRAIL). It is a pro-apoptotic member of the tumor necrosis factor cytokine family and activates the extrinsic apoptotic pathway by the death receptors DR4 and DR5. In a phase I dose escalation trial of Apo2L/ TRAIL in 71 advanced cancer patients, five had chondrosarcoma and two of these demonstrated prolonged (greater than 3 years) partial response to the continued administration of the agent. ${ }^{59}$ Additionally, marked necrosis was observed at time of 
surgical resection in an additional two. Although encouraging, it must be remembered that the above strategies are very early stages of evaluation.

Although there are numerous agents reported that are effective against chondrosarcoma in culture, delivery of these to real tumors will always be a technical hurdle because of the low vascular penetration and abundant matrix encasing the malignant cells.

\section{Surgical Management}

Standard management of chondrosarcoma consists of wide surgical resection without the benefit of adjuvant radiation or chemotherapy. As with all bone sarcomas skeletal reconstruction is usually necessary and is most often in the form of metallic endoprostheses, allografts or alloprosthetic composites. ${ }^{1}$ Recently however, in cases of low-grade lesions, some support has arisen for curettage with the use of an adjuvant such as phenol, cryosurgery, or argon laser. Mohler et al reviewed 46 patients that had intralesional curettage and cryotherapy for atypical enchondromas and low-grade chondrosarcomas and demonstrated a $4.3 \%$ local recurrence rate ${ }^{60}$ The two recurrences underwent wide reexcision and were disease free at 30 and 36 months respectively.

The Instituto Rizzoli reviewed patients who had undergone intralesional curettage of lowgrade chondrosarcomas and compared them to those who had wide resection. They found no recurrences in the resection group and two of fifteen in the curettage group. The two recurrences were managed with re-excision and no patient developed distant disease. The functional score was higher in those patients undergoing curettage. ${ }^{61}$ Although these studies are encouraging for using lesser surgery in low-grade chondrosarcoma, further study with larger patient cohorts are needed to determine the safety and efficacy of intralesional curettage. In the setting of secondary chondrosarcomas arising from osteochondromas, wide excision of the entire lesion is recommended including the associated cartilaginous cap.

The local recurrence and metastasis rate for low and intermediate grade chondrosarcomas are extremely low if complete excision is achieved. Overall survival rates are still disappointingly low in high-grade tumors, with $50 \%$ long-term survival. Dedifferentiated chondrosarcomas are worse, having $20 \%$ survival rates at 5 years. ${ }^{62}$ As with most other sarcomas, it is apparent that novel breakthrough therapies are needed.

\section{EWING SARCOMA}

\section{Overview}

Ewing sarcoma is a small, round, blue cell malignancy that is the second most common primary bone malignancy in children and adolescents. It typically affects individuals in the first three decades of life. The long tubular bones are the most common location with the femur (25\%) being the single most common followed by the tibia, fibula, pelvic girdle, and the ribs. ${ }^{1}$ Although commonly described as a diaphyseal lesion, meta-diaphyseal and metaphyseal involvement is twice as common. Histologically, uniform, small round blue, relatively undifferentiated cells with scant cytoplasm are visualized.(Fig 3D and 3E)

Immunohistochemical, anlalysis of Ewing's sarcoma demonstrates non-specific but strong staining for vimentin and S-100. The vast majority of tumors are positive for the surface antigen, CD99/MIC2. ${ }^{63}$ However, CD99 is not specific to Ewing's sarcoma and is seen in various other malignancies such as lymphomas, leukemias and rhabdomyosarcoma. Thus the diagnosis often rests on the demonstration of the characteristic $t(11 ; 22)$ translocation by either cytogenetics or FISH (fluorescent in situ hybridization. ${ }^{64}$ Poor prognostic factors in Ewing's sarcoma include axial skeletal location (particularly the pelvis) size greater than 8 
$\mathrm{cm}$, and metastatic disease at diagnosis. Unlike other sarcomas, staging includes bone marrow biopsy as occult bone metastases are not uncommon.

\section{Etiology}

Most cases of Ewing's sarcoma contain the $(11 ; 22)(\mathrm{q} 24 ; \mathrm{q} 12)$ chromosomal translocation that encodes the EWS/FLI oncoprotein. The oncogenic potential of this fusion product has been demonstrated by transforming immortalized murine NIH3T3 cells. ${ }^{65}$ Although persistent EWS/FLI1 expression is needed to maintain the malignant phenotype of Ewing's sarcoma cells it should be noted that no normal human cells have been transformed in this fashion to date ${ }^{66,67}$ The tissue or cell of origin is not known. Prevailing thought implicates either neural ectoderm or mesenchymal stem cells. ${ }^{68}$ A neuroectodermal origin is supported by the expression of neuroectodermal surface antigens on Ewing's cells, that the entity, primitive neuroectodermal tumor and Ewing's sarcoma share the same $t(11 ; 22)$ translocation, and that neuronal developmental genes are expressed in Ewing's cells. ${ }^{69,70}$ More recently, using a tetracycline-inducible EWS-FLI1 expression system in a rhabdomyosarcoma cell line, it has been shown that the presence of EWS/FLI induces the expression of genes normally associated with neural crest development. The authors suggested that the neuroectodermal phenotype of Ewing's sarcoma might more accurately reflect aberrant transcription rather than suggesting a neural cell of origin. ${ }^{71-73}$

Other studies have suggested that Ewing's sarcoma is derived from a mesenchymal stem or progenitor cell. Introducing EWS/FLI into primary murine bone marrow cells or mesenchymal progenitor cells resulted in tumors with small round cell morphology and expression of $\mathrm{CD} 99^{74}$. Gene expression profiles of these tumors displayed marked similarities to human Ewing's sarcoma. ${ }^{66,75}$ Moreover, in a complementary assay, RNAi silencing of EWS/FLI expression in Ewing sarcoma cell lines resulted in mesenchymal stem cell (MSC) gene expression profile and inducibility of osteogenic and adipogenic lineages consistent with a base MSC like state. ${ }^{76}$ Despite these intriguing data, the cell of origin remains unknown.

\section{Imaging}

The imaging evaluation for Ewing's sarcoma is similar to that of osteosarcoma. Plain radiographs in two orthogonal planes usually reveal a permeative destructive bone lesion along with the shadow from an associated soft tissue mass. (Fig 3A) Radiographs of the entire bone commonly identifie a metaphyseal or diaphyseal lesion with classic features including "onion-skinning" of the periosteum. Expansion of the tumor and rapid remodeling of the overlying periosteum with associated mineralization leads to this characteristic finding. Ewing sarcoma, however, is not the only etiology to have rapid periosteal remodeling as this can be seen in osteomyelitis, osteosarcoma, and other aggressive lesions.

The gold standard for detailed imaging is Magnetic Resonance Imaging (MRI). MRI allows determination of both intra and extra-medullary extent of disease. Classically, Ewing's sarcoma exhibits a large soft tissue mass out of proportion to the amount of bone destruction. (Fig 3B) MRI allows accurate surgical and/or radiotherapy planning. Skip metastases can be visualized and for this reason the entire involved bone should be included on the scan. Additionally, recent data suggests that a change in the size and signal of the tumor post-chemotherapy may predict local recurrence and survival. ${ }^{77}$ (Fig 3C)

Technitium bone scans are recommended to assess for local activity or distant bony metastasis. A CT scan of the chest is performed to assess for metastatic disease in the lung parenchyma which is the most common distant site. 
Currently, the benefit of a PET scan is unknown and not part of the standardized initial staging protocol. PET scans have been combined with CT scans with good results for restaging and surveillance of metastasis. The use of 18-fluoro-deoxyglucose has been shown to be useful for the detection of local recurrence and distant metastasis. ${ }^{78}$ It does however carry a significant false positive rate and larger studies are underway to address its specificity and sensitivity.

\section{Systemic Therapy}

The standard neo-adjuvant chemotherapy regimen consists of cyclophosphamide, vincristine, and doxorubicin alternating with etoposide and ifosfamide. This can be combined with radiation, surgery or both. Current event-free survival and overall survival have been reported as high as $65 \%$ and $82 \%$ with localized disease and $25 \%$ and $39 \%$ in those with detectable metastatic disease. ${ }^{79-81}$

Current studies focus on intensifying the alkylating agents and administering more intense chemotherapy over a shorter time-period. Picci et al., in a review of the experience at the Rizzoli Institute, found significantly improved survival when there was a good histological response to neoadjuvant chemotherapy. ${ }^{82,83}$

\section{Surgical Management}

Surgical management of Ewing sarcoma includes wide resection of lesions in the appendicular skeleton and selected resection for lesions in the axial skeleton. Appropriate surgical treatment results in less than a $10 \%$ local recurrence rate. ${ }^{84,85}$

The benefits of surgical resection and reconstruction after neo-adjuvant chemotherapy include complete removal of all tumor cells, including potentially drug resistant cells, thus minimizing local recurrence while also providing a stable construct for ambulation or upper extremity function. As with osteosarcoma, histologic determination of the percent necrosis within the tumor allows for prognoses stratification. Adjuvant chemotherapy may be altered if a poor response is seen. The recent French Society of Paediatric Oncology study showed that event free survival at 5 years for patients with less than 5\% viable tumor, 5\% to 30\% viable tumor, and greater than $30 \%$ viable tumor were $75 \%, 48 \%$, and $20 \%$, respectively. ${ }^{86}$

Positive surgical margins are correlated with local recurrence. Patients with appropriate margins have improved 5-year event-free survival compared to those with intralesional or marginal resections. ${ }^{87}$ In cases with positive margins, repeat resection should be undertaken along with possible adjuvant radiation therapy. However, in cases of planned intralesional debulking followed by radiation therapy, the local control rates are not improved by radiotherapy. ${ }^{84,88}$ Therefore, in instances where complete surgical extirpation cannot be achieved, consideration should be given to local management with radiation alone. Surgical resection must be weighed against its morbidity and the ability to preserve or reconstruct skeletal function. Significant controversy exists over the definitive local control modality for Ewing's of the pelvis and spine and collaborative studies are ongoing to help determine the relative benefits of surgical resection and radiation in this setting.

The vast majority of patients can be managed with limb salvage surgery, avoiding amputation. Pre-requisites for limb salvage include complete tumor resection, the ability to retain the critical neuro-vascular structures of the extremity, and the creation of a stable construct for ambulation. Although previously considered a contraindication to limb salvage, pathologic fracture has not been found to have higher incidence of recurrence after limb salvage. Resections that involve neurologic structures including the sciatic, tibial or peroneal nerves are no longer considered absolute indications for amputation as these patients can do very well with gait training and bracing. Typically, lesions in the foot or 
distal leg are more often considered for amputation because of the high morbidity associated with flap coverage, and the excellent function of modern orthoses.

Reconstructive options are similar to osteosarcoma, including osteoarticular allografts, allograft prosthetic composites, mega-prosthetic implants, amputation, rotationplasty, and free tissue transfer.

\section{Radiotherapy}

Ewing's sarcoma is the most radiosensitive of the bone sarcomas. Radiotherapy may be used as the primary local control modality or combined with surgery. ${ }^{89,90}$ Indications for radiotherapy include unplanned positive margins in resected tumors, unresectable tumors, tumors for which resection would cause unacceptable morbidity (e.g. acetabulum and spine) and in tumors that have poor chemotherapeutic response. ${ }^{91}$ Additionally, radiation is often used in addition to surgery and chemotherapy in a neoadjuvant fashion.

Treatment protocols include the use of external beam radiotherapy that incorporate the gross tumor volume with an adequate margin, usually five to ten centimeters. Typical treatments include 55.8 to $60.0 \mathrm{~Gy}$ for primary local control, without surgery. In cases with surgical intervention, 45Gy is administered preoperatively. Postoperative doses are higher secondary to local tissue hypoxia. Most treatment is given by either 3D conformal or intensity modulated radiation therapy. The role of proton beam radiation in the spine and skull is well accepted, its role in more accessible sites remains to be determined.

The long-term complications from radiotherapy have become more apparent since neoadjuvant chemotherapy has resulted in higher survival rates. In addition, as most patients are skeletally immature, these complications include arthrofibrosis, leg-length discrepancy, pathologic fracture, and secondary malignancies. ${ }^{92}$

\section{Future Studies}

Future treatment protocols are likely to be derived from elucidation of the molecular abnormalities driving Ewing's sarcoma. The most obvious target is EWS/FLI-1 function itself, which is necessary but not sufficient for the malignant phenotype of Ewing's sarcoma. Indeed, pre-clinical work blocking the oncogenic protein interaction of EWS-FLI-1 with RNA helicase A using a small molecule inhibitor inhibited tumor growth in an orthotopic xenograft model..$^{93}$ Further, it has been shown that administration of EWS/FLI-1 antisense oligonucleotides and rapamycin induced apotosis of Ewings cells in culture. ${ }^{94}$ This in vitro work was subsequently supported by demonstration of a decreased tumor growth in an siRNA knockdown murine model. ${ }^{95}$ Unfortuanately, direct interference with EWS/FLI-1 has proved difficult to evaluate beyond in vitro and rodent models.

In 1990, Yee et al first demonstrated that Ewing's cell lines expressed both the insulin like growth factor 1 (IGF-1) and its receptor, IGF-1R. They further showed that antibodies blocking IGF-1R slowed cell growth in culture. ${ }^{96}$ Subsequent work by others has shown that the IGF pathway may be regulated by EWS/FLI1 making it an intriguing therapeutic target. Indeed, several pre-clinical experiments and early phase clinical trials have shown promise utilizing small molecule and antibody inhibitors of the IGF pathway. ${ }^{97-99}$ However, IGF signaling inhibition alone has benefitted only a very few patients in these studies. It has recently been demonstrated that failure of monotherapy with IGF-1R inhibitors may be due the cells ability to switch pathways from IGF-1 to IGF-2 and its associated enhanced receptor, IR-A. ${ }^{100}$ Another potential mode of failure in single agent IGF-1 blockade is that mTOR (mammalian target of rapamycin) expression may be induced when IGF-1R is blocked. Thus combination therapy with an mTOR inhibitor may be beneficial. ${ }^{101}$ Because the P13 kinase and MAP kinase pathways are constitutively activated in Ewing's sarcoma 
secondary to IGF-1R autocrine feedback loops, P13 kinase inhibitors being developed in other malignancies may also offer benefit. ${ }^{102}$

Although CD99 is not specific to Ewing's sarcoma, its blockade has been suggested to be a target for therapy. Antibody inhibition induces apoptosis in culture, slows tumor formation in vivo and acts synergistically with doxorubicin and vincristine in vitro. ${ }^{103,104}$ Recent work has been done suggesting CD99 may have some role in pathogenesis. Rocchi et al, in knockdown experiments using Ewing's sarcoma cell lines, demonstrated that knockdown of CD99 resulted in decreased cell growth as well as smaller tumors with fewer metastases in a mouse model. ${ }^{105}$

Immunotherapy has had a checkered past in the treatment of sarcomas. Recently, however investigators have shown data in support of the use of expanded ex vivo natural killer (NK) cells in Ewing's sarcoma. ${ }^{106} \mathrm{NK}$ cytotoxicity is induced via activating receptors, the most studied of which is NKG2D. The authors were able to expand NK cells in culture and demonstrated significant cytotoxicity against Ewing's cells mediated by the NKG2D ligand and receptor. Further, they were able to increase the cytotoxic effect when the cells were treated with radiation that purportedly increased the expression of the NKG2D ligand in response to stress. These and experiments like them offer some optimism for the development of complementary therapies to augment the current cyotoxic agents.

In summary, we have made large strides in our understanding of the molecular and cellular underpinnings of these three boney malignancies. However, this has not yet led to the hoped for changes in survival for our patients. Further study, perhaps focusing on intra and intertumoral heterogeneity may yield more useful data upon which to build more effective therapies.

\section{Acknowledgments}

The authors acknowledge support of a grant from the NCI in the formation of this manuscript: RO1 CA 137186. PI: Gibbs, CP

\section{References}

1. Gibbs CP Jr. Weber K, Scarborough MT. Malignant bone tumors. Instr Course Lect. 2002; 51:413428. [PubMed: 12064130]

2. Meyers PA, Schwartz CL, Krailo M, et al. Osteosarcoma: a randomized, prospective trial of the addition of ifosfamide and/or muramyl tripeptide to cisplatin, doxorubicin, and high-dose methotrexate. J Clin Oncol. 2005 Mar 20; 23(9):2004-2011. [PubMed: 15774791]

3. Jaffe N, Carrasco H, Raymond K, Ayala A, Eftekhari F. Can cure in patients with osteosarcoma be achieved exclusively with chemotherapy and abrogation of surgery? Cancer. 2002 Nov 15; 95(10): 2202-2210. [PubMed: 12412175]

4. Chi SN, Conklin LS, Qin J, et al. The patterns of relapse in osteosarcoma: the Memorial SloanKettering experience. Pediatr Blood Cancer. 2004 Jan; 42(1):46-51. [PubMed: 14752794]

5. Wuisman P, Enneking WF. Prognosis for patients who have osteosarcoma with skip metastasis. J Bone Joint Surg Am. 1990 Jan; 72(1):60-68. [PubMed: 2295674]

6. Sandberg AA, Bridge JA. Updates on the cytogenetics and molecular genetics of bone and soft tissue tumors: osteosarcoma and related tumors. Cancer Genet Cytogenet. 2003 Aug; 145(1):1-30. [PubMed: 12885459]

7. Miller CW, Aslo A, Won A, Tan M, Lampkin B, Koeffler HP. Alterations of the p53, Rb and MDM2 genes in osteosarcoma. J Cancer Res Clin Oncol. 1996; 122(9):559-565. [PubMed: $8781571]$ 
8. Feugeas O, Guriec N, Babin-Boilletot A, et al. Loss of heterozygosity of the RB gene is a poor prognostic factor in patients with osteosarcoma. J Clin Oncol. 1996 Feb; 14(2):467-472. [PubMed: 8636759]

9. Siddiqui NH, Jani J. Osteosarcoma metastatic to adrenal gland diagnosed by fine-needle aspiration. Diagn Cytopathol. 2005 Sep; 33(3):201-204. [PubMed: 16078243]

10. Ragland BD, Bell WC, Lopez RR, Siegal GP. Cytogenetics and molecular biology of osteosarcoma. Lab Invest. 2002 Apr; 82(4):365-373. [PubMed: 11950895]

11. Gibbs CP, Kukekov VG, Reith JD, et al. Stem-like cells in bone sarcomas: implications for tumorigenesis. Neoplasia. 2005 Nov; 7(11):967-976. [PubMed: 16331882]

12. Wu C, Wei Q, Utomo V, et al. Side population cells isolated from mesenchymal neoplasms have tumor initiating potential. Cancer Res. 2007 Sep 1; 67(17):8216-8222. [PubMed: 17804735]

13. Levings PP, McGarry SV, Currie TP, et al. Expression of an exogenous human Oct-4 promoter identifies tumor-initiating cells in osteosarcoma. Cancer Res. 2009 Jul 15; 69(14):5648-5655. [PubMed: 19584295]

14. Stokkel MP, Linthorst MF, Borm JJ, Taminiau AH, Pauwels EK. A reassessment of bone scintigraphy and commonly tested pretreatment biochemical parameters in newly diagnosed osteosarcoma. J Cancer Res Clin Oncol. 2002 Jul; 128(7):393-399. [PubMed: 12136254]

15. Costelloe CM, Macapinlac HA, Madewell JE, et al. 18F-FDG PET/CT as an indicator of progression-free and overall survival in osteosarcoma. J Nucl Med. 2009 Mar; 50(3):340-347. [PubMed: 19258257]

16. Okada K, Frassica FJ, Sim FH, Beabout JW, Bond JR, Unni KK. Parosteal osteosarcoma. A clinicopathological study. J Bone Joint Surg Am. 1994 Mar; 76(3):366-378. [PubMed: 8126042]

17. Schwab JH, Antonescu CR, Athanasian EA, Boland PJ, Healey JH, Morris CD. A comparison of intramedullary and juxtacortical low-grade osteogenic sarcoma. Clin Orthop Relat Res. 2008 Jun; 466(6):1318-1322. [PubMed: 18425560]

18. Eilber FR, Rosen G. Adjuvant chemotherapy for osteosarcoma. Semin Oncol. 1989 Aug; 16(4): 312-322. [PubMed: 2667146]

19. Link MP, Goorin AM, Miser AW, et al. The effect of adjuvant chemotherapy on relapse-free survival in patients with osteosarcoma of the extremity. N Engl J Med. 1986 Jun 19; 314(25): 1600-1606. [PubMed: 3520317]

20. Ferrari S, Smeland S, Mercuri M, et al. Neoadjuvant chemotherapy with high-dose Ifosfamide, high-dose methotrexate, cisplatin, and doxorubicin for patients with localized osteosarcoma of the extremity: a joint study by the Italian and Scandinavian Sarcoma Groups. J Clin Oncol. 2005 Dec 1; 23(34):8845-8852. [PubMed: 16246977]

21. Glasser DB, Lane JM, Huvos AG, Marcove RC, Rosen G. Survival, prognosis, and therapeutic response in osteogenic sarcoma. The Memorial Hospital experience. Cancer. 1992 Feb 1; 69(3): 698-708. [PubMed: 1730120]

22. Zhou Q, Deng Z, Zhu Y, Long H, Zhang S, Zhao J. mTOR/p70S6K signal transduction pathway contributes to osteosarcoma progression and patients' prognosis. Med Oncol. 2010 Dec; 27(4): 1239-1245. [PubMed: 19936974]

23. Vemulapalli S, Mita A, Alvarado Y, Sankhala K, Mita M. The emerging role of mammalian target of rapamycin inhibitors in the treatment of sarcomas. Target Oncol. 2011 Mar; 6(1):29-39. [PubMed: 21533543]

24. Mita MM, Mita AC, Chu QS, et al. Phase I trial of the novel mammalian target of rapamycin inhibitor deforolimus (AP23573; MK-8669) administered intravenously daily for 5 days every 2 weeks to patients with advanced malignancies. J Clin Oncol. 2008 Jan 20; 26(3):361-367. [PubMed: 18202410]

25. Moriceau G, Ory B, Mitrofan L, et al. Zoledronic acid potentiates mTOR inhibition and abolishes the resistance of osteosarcoma cells to RAD001 (Everolimus): pivotal role of the prenylation process. Cancer Res. 2010 Dec 15; 70(24):10329-10339. [PubMed: 20971812]

26. Cirocchi R, Farinella E, La Mura F, et al. Efficacy of surgery and imatinib mesylate in the treatment of advanced gastrointestinal stromal tumor: a systematic review. Tumori. 2010 MayJun; 96(3):392-399. [PubMed: 20845798] 
27. Scotlandi K, Picci P, Kovar H. Targeted therapies in bone sarcomas. Curr Cancer Drug Targets. 2009 Nov; 9(7):843-853. [PubMed: 20025572]

28. Ahmed SF, Farquharson C. The effect of GH and IGF1 on linear growth and skeletal development and their modulation by SOCS proteins. J Endocrinol. 2010 Sep; 206(3):249-259. [PubMed: 20631046]

29. Scotlandi K, Picci P. Targeting insulin-like growth factor 1 receptor in sarcomas. Curr Opin Oncol. 2008 Jul; 20(4):419-427. [PubMed: 18525338]

30. Kolb EA, Gorlick R, Houghton PJ, et al. Initial testing (stage 1) of a monoclonal antibody (SCH 717454) against the IGF-1 receptor by the pediatric preclinical testing program. Pediatr Blood Cancer. 2008 Jun; 50(6):1190-1197. [PubMed: 18260118]

31. Kurmasheva RT, Dudkin L, Billups C, Debelenko LV, Morton CL, Houghton PJ. The insulin-like growth factor-1 receptor-targeting antibody, CP-751,871, suppresses tumor-derived VEGF and synergizes with rapamycin in models of childhood sarcoma. Cancer Res. 2009 Oct 1; 69(19): 7662-7671. [PubMed: 19789339]

32. Meyers PA, Schwartz CL, Krailo MD, et al. Osteosarcoma: the addition of muramyl tripeptide to chemotherapy improves overall survival--a report from the Children's Oncology Group. J Clin Oncol. 2008 Feb 1; 26(4):633-638. [PubMed: 18235123]

33. Chou AJ, Kleinerman ES, Krailo MD, et al. Addition of muramyl tripeptide to chemotherapy for patients with newly diagnosed metastatic osteosarcoma: a report from the Children's Oncology Group. Cancer. 2009 Nov 15; 115(22):5339-5348. [PubMed: 19637348]

34. Shin KH, Rougraff BT, Simon MA. Oncologic outcomes of primary bone sarcomas of the pelvis. Clin Orthop Relat Res. 1994 Jul.(304):207-217. [PubMed: 8020218]

35. Brien EW, Mirra JM, Kerr R. Benign and malignant cartilage tumors of bone and joint: their anatomic and theoretical basis with an emphasis on radiology, pathology and clinical biology. I. The intramedullary cartilage tumors. Skeletal Radiol. 1997 Jun; 26(6):325-353. [PubMed: 9229417]

36. Bruns J, Elbracht M, Niggemeyer O. Chondrosarcoma of bone: an oncological and functional follow-up study. Ann Oncol. 2001 Jun; 12(6):859-864. [PubMed: 11484965]

37. Tiet TD, Hopyan S, Nadesan P, et al. Constitutive hedgehog signaling in chondrosarcoma upregulates tumor cell proliferation. Am J Pathol. 2006 Jan; 168(1):321-330. [PubMed: 16400033]

38. Schrage YM, Lam S, Jochemsen AG, et al. Central chondrosarcoma progression is associated with $\mathrm{pRb}$ pathway alterations: CDK4 down-regulation and p16 overexpression inhibit cell growth in vitro. J Cell Mol Med. 2009 Sep; 13(9A):2843-2852. [PubMed: 18624751]

39. Larramendy ML, Tarkkanen M, Valle J, et al. Gains, losses, and amplifications of DNA sequences evaluated by comparative genomic hybridization in chondrosarcomas. Am J Pathol. 1997 Feb; 150(2):685-691. [PubMed: 9033281]

40. van Beerendonk HM, Rozeman LB, Taminiau AH, et al. Molecular analysis of the INK4A/ INK4A-ARF gene locus in conventional (central) chondrosarcomas and enchondromas: indication of an important gene for tumour progression. J Pathol. 2004 Mar; 202(3):359-366. [PubMed: 14991902]

41. Okada T, Tanaka K, Nakatani F, et al. Involvement of P-glycoprotein and MRP1 in resistance to cyclic tetrapeptide subfamily of histone deacetylase inhibitors in the drug-resistant osteosarcoma and Ewing's sarcoma cells. Int J Cancer. 2006 Jan 1; 118(1):90-97. [PubMed: 16049968]

42. Sakimura R, Tanaka K, Yamamoto S, et al. The effects of histone deacetylase inhibitors on the induction of differentiation in chondrosarcoma cells. Clin Cancer Res. 2007 Jan 1; 13(1):275-282. [PubMed: 17200366]

43. Marco RA, Gitelis S, Brebach GT, Healey JH. Cartilage tumors: evaluation and treatment. J Am Acad Orthop Surg. 2000 Sep-Oct; 8(5):292-304. [PubMed: 11029557]

44. Murphey MD, Flemming DJ, Boyea SR, Bojescul JA, Sweet DE, Temple HT. Enchondroma versus chondrosarcoma in the appendicular skeleton: differentiating features. Radiographics. 1998 Sep-Oct; 18(5):1213-1237. quiz 1244-1237. [PubMed: 9747616]

45. Feldman F, Van Heertum R, Saxena C, Parisien M. 18FDG-PET applications for cartilage neoplasms. Skeletal Radiol. 2005 Jul; 34(7):367-374. [PubMed: 15937711] 
46. Brenner W, Conrad EU, Eary JF. FDG PET imaging for grading and prediction of outcome in chondrosarcoma patients. Eur J Nucl Med Mol Imaging. 2004 Feb; 31(2):189-195. [PubMed: 15129700]

47. Jamil N, Howie S, Salter DM. Therapeutic molecular targets in human chondrosarcoma. Int J Exp Pathol. 2010 Oct; 91(5):387-393. [PubMed: 21078112]

48. Nguyen QN, Chang EL. Emerging role of proton beam radiation therapy for chordoma and chondrosarcoma of the skull base. Curr Oncol Rep. 2008 Jul; 10(4):338-343. [PubMed: 18778560]

49. Wyman JJ, Hornstein AM, Meitner PA, et al. Multidrug resistance-1 and p-glycoprotein in human chondrosarcoma cell lines: expression correlates with decreased intracellular doxorubicin and in vitro chemoresistance. J Orthop Res. 1999 Nov; 17(6):935-940. [PubMed: 10632461]

50. Terek RM, Healey JH, Garin-Chesa P, Mak S, Huvos A, Albino AP. p53 mutations in chondrosarcoma. Diagn Mol Pathol. 1998 Feb; 7(1):51-56. [PubMed: 9646035]

51. Mitchell AD, Ayoub K, Mangham DC, Grimer RJ, Carter SR, Tillman RM. Experience in the treatment of dedifferentiated chondrosarcoma. J Bone Joint Surg Br. 2000 Jan; 82(1):55-61. [PubMed: 10697315]

52. Dickey ID, Rose PS, Fuchs B, et al. Dedifferentiated chondrosarcoma: the role of chemotherapy with updated outcomes. J Bone Joint Surg Am. 2004 Nov; 86-A(11):2412-2418. [PubMed: 15523011]

53. Grimer RJ, Gosheger G, Taminiau A, et al. Dedifferentiated chondrosarcoma: prognostic factors and outcome from a European group. Eur J Cancer. 2007 Sep; 43(14):2060-2065. [PubMed: 17720491]

54. Workman P, Burrows F, Neckers L, Rosen N. Drugging the cancer chaperone HSP90: combinatorial therapeutic exploitation of oncogene addiction and tumor stress. Ann N Y Acad Sci. 2007 Oct.1113:202-216. [PubMed: 17513464]

55. Hollingshead M, Alley M, Burger AM, et al. In vivo antitumor efficacy of 17-DMAG (17dimethylaminoethylamino-17-demethoxygeldanamycin hydrochloride), a water-soluble geldanamycin derivative. Cancer Chemother Pharmacol. 2005 Aug; 56(2):115-125. [PubMed: 15791458]

56. Trepel J, Mollapour M, Giaccone G, Neckers L. Targeting the dynamic HSP90 complex in cancer. Nat Rev Cancer. 2010 Aug; 10(8):537-549. [PubMed: 20651736]

57. Pacey S, Wilson RH, Walton M, et al. A phase I study of the heat shock protein 90 inhibitor alvespimycin (17-DMAG) given intravenously to patients with advanced solid tumors. Clin Cancer Res. 2011 Mar 15; 17(6):1561-1570. [PubMed: 21278242]

58. David E, Guihard P, Brounais B, et al. Direct anti-cancer effect of oncostatin M on chondrosarcoma. Int J Cancer. 2011 Apr 15; 128(8):1822-1835. [PubMed: 21344373]

59. Herbst RS, Eckhardt SG, Kurzrock R, et al. Phase I dose-escalation study of recombinant human Apo2L/TRAIL, a dual proapoptotic receptor agonist, in patients with advanced cancer. J Clin Oncol. 2010 Jun 10; 28(17):2839-2846. [PubMed: 20458040]

60. Mohler DG, Chiu R, McCall DA, Avedian RS. Curettage and cryosurgery for low-grade cartilage tumors is associated with low recurrence and high function. Clin Orthop Relat Res. 2010 Oct; 468(10):2765-2773. [PubMed: 20574801]

61. Donati D, Colangeli S, Colangeli M, Di Bella C, Bertoni F. Surgical treatment of grade I central chondrosarcoma. Clin Orthop Relat Res. 2010 Feb; 468(2):581-589. [PubMed: 19727994]

62. Bruns J, Fiedler W, Werner M, Delling G. Dedifferentiated chondrosarcoma--a fatal disease. J Cancer Res Clin Oncol. 2005 Jun; 131(6):333-339. [PubMed: 15785935]

63. Franchi A, Pasquinelli G, Cenacchi G, et al. Immunohistochemical and ultrastructural investigation of neural differentiation in Ewing sarcoma/PNET of bone and soft tissues. Ultrastruct Pathol. 2001 May-Jun; 25(3):219-225. [PubMed: 11465478]

64. Taylor C, Patel K, Jones T, Kiely F, De Stavola BL, Sheer D. Diagnosis of Ewing's sarcoma and peripheral neuroectodermal tumour based on the detection of $\mathrm{t}(11 ; 22)$ using fluorescence in situ hybridisation. Br J Cancer. 1993 Jan; 67(1):128-133. [PubMed: 8381297]

65. Zwerner JP, Guimbellot J, May WA. EWS/FLI function varies in different cellular backgrounds. Exp Cell Res. 2003 Nov 1; 290(2):414-419. [PubMed: 14567998] 
66. Riggi N, Suva ML, Suva D, et al. EWS-FLI-1 expression triggers a Ewing's sarcoma initiation program in primary human mesenchymal stem cells. Cancer Res. 2008 Apr 1; 68(7):2176-2185. [PubMed: 18381423]

67. Kinsey M, Smith R, Lessnick SL. NR0B1 is required for the oncogenic phenotype mediated by EWS/FLI in Ewing's sarcoma. Mol Cancer Res. 2006 Nov; 4(11):851-859. [PubMed: 17114343]

68. Toomey EC, Schiffman JD, Lessnick SL. Recent advances in the molecular pathogenesis of Ewing's sarcoma. Oncogene. 2010 Aug 12; 29(32):4504-4516. [PubMed: 20543858]

69. Kovar H. Ewing's sarcoma and peripheral primitive neuroectodermal tumors after their genetic union. Curr Opin Oncol. 1998 Jul; 10(4):334-342. [PubMed: 9702401]

70. Staege MS, Hutter C, Neumann I, et al. DNA microarrays reveal relationship of Ewing family tumors to both endothelial and fetal neural crest-derived cells and define novel targets. Cancer Res. 2004 Nov 15; 64(22):8213-8221. [PubMed: 15548687]

71. Hu-Lieskovan S, Zhang J, Wu L, Shimada H, Schofield DE, Triche TJ. EWS-FLI1 fusion protein up-regulates critical genes in neural crest development and is responsible for the observed phenotype of Ewing's family of tumors. Cancer Res. 2005 Jun 1; 65(11):4633-4644. [PubMed: 15930281]

72. Lessnick SL, Dacwag CS, Golub TR. The Ewing's sarcoma oncoprotein EWS/FLI induces a p53dependent growth arrest in primary human fibroblasts. Cancer Cell. 2002 May; 1(4):393-401. [PubMed: 12086853]

73. Rorie CJ, Thomas VD, Chen P, Pierce HH, O'Bryan JP, Weissman BE. The Ews/Fli-1 fusion gene switches the differentiation program of neuroblastomas to Ewing sarcoma/peripheral primitive neuroectodermal tumors. Cancer Res. 2004 Feb 15; 64(4):1266-1277. [PubMed: 14973077]

74. Castillero-Trejo Y, Eliazer S, Xiang L, Richardson JA, Ilaria RL Jr. Expression of the EWS/FLI-1 oncogene in murine primary bone-derived cells Results in EWS/FLI-1-dependent, ewing sarcomalike tumors. Cancer Res. 2005 Oct 1; 65(19):8698-8705. [PubMed: 16204038]

75. Miyagawa Y, Okita H, Nakaijima H, et al. Inducible expression of chimeric EWS/ETS proteins confers Ewing's family tumor-like phenotypes to human mesenchymal progenitor cells. Mol Cell Biol. 2008 Apr; 28(7):2125-2137. [PubMed: 18212050]

76. Tirode F, Laud-Duval K, Prieur A, Delorme B, Charbord P, Delattre O. Mesenchymal stem cell features of Ewing tumors. Cancer Cell. 2007 May; 11(5):421-429. [PubMed: 17482132]

77. Lemmi MA, Fletcher BD, Marina NM, et al. Use of MR imaging to assess results of chemotherapy for Ewing sarcoma. AJR Am J Roentgenol. 1990 Aug; 155(2):343-346. [PubMed: 2115265]

78. Hawkins DS, Schuetze SM, Butrynski JE, et al. [18F]Fluorodeoxyglucose positron emission tomography predicts outcome for Ewing sarcoma family of tumors. J Clin Oncol. 2005 Dec 1; 23(34):8828-8834. [PubMed: 16314643]

79. Rodriguez-Galindo C, Navid F, Liu T, Billups CA, Rao BN, Krasin MJ. Prognostic factors for local and distant control in Ewing sarcoma family of tumors. Ann Oncol. 2008 Apr; 19(4):814820. [PubMed: 17998282]

80. Esiashvili N, Goodman M, Marcus RB Jr. Changes in incidence and survival of Ewing sarcoma patients over the past 3 decades: Surveillance Epidemiology and End Results data. J Pediatr Hematol Oncol. 2008 Jun; 30(6):425-430. [PubMed: 18525458]

81. Grier HE, Krailo MD, Tarbell NJ, et al. Addition of ifosfamide and etoposide to standard chemotherapy for Ewing's sarcoma and primitive neuroectodermal tumor of bone. N Engl J Med. 2003 Feb 20; 348(8):694-701. [PubMed: 12594313]

82. Picci P, Rougraff BT, Bacci G, et al. Prognostic significance of histopathologic response to chemotherapy in nonmetastatic Ewing's sarcoma of the extremities. J Clin Oncol. 1993 Sep; 11(9): 1763-1769. [PubMed: 8355043]

83. Wunder JS, Paulian G, Huvos AG, Heller G, Meyers PA, Healey JH. The histological response to chemotherapy as a predictor of the oncological outcome of operative treatment of Ewing sarcoma. J Bone Joint Surg Am. 1998 Jul; 80(7):1020-1033. [PubMed: 9698007]

84. Bacci G, Forni C, Longhi A, et al. Long-term outcome for patients with non-metastatic Ewing's sarcoma treated with adjuvant and neoadjuvant chemotherapies. 402 patients treated at Rizzoli between 1972 and 1992. Eur J Cancer. 2004 Jan; 40(1):73-83. [PubMed: 14687792] 
85. Bacci G, Longhi A, Briccoli A, Bertoni F, Versari M, Picci P. The role of surgical margins in treatment of Ewing's sarcoma family tumors: experience of a single institution with 512 patients treated with adjuvant and neoadjuvant chemotherapy. Int J Radiat Oncol Biol Phys. 2006 Jul 1; 65(3):766-772. [PubMed: 16626886]

86. Oberlin O, Deley MC, Bui BN, et al. Prognostic factors in localized Ewing's tumours and peripheral neuroectodermal tumours: the third study of the French Society of Paediatric Oncology (EW88 study). Br J Cancer. 2001 Nov 30; 85(11):1646-1654. [PubMed: 11742482]

87. Sluga M, Windhager R, Lang S, et al. The role of surgery and resection margins in the treatment of Ewing's sarcoma. Clin Orthop Relat Res. 2001 Nov.(392):394-399. [PubMed: 11716413]

88. Laskar S, Mallick I, Gupta T, Muckaden MA. Post-operative radiotherapy for Ewing sarcoma: when, how and how much? Pediatr Blood Cancer. 2008 Nov; 51(5):575-580. [PubMed: 18561167]

89. Indelicato DJ, Keole SR, Shahlaee AH, Shi W, Morris CG, Marcus RB Jr. Definitive radiotherapy for ewing tumors of extremities and pelvis: long-term disease control, limb function, and treatment toxicity. Int J Radiat Oncol Biol Phys. 2008 Nov 1; 72(3):871-877. [PubMed: 18455323]

90. Shi W, Indelicato DJ, Keole SR, et al. Radiation treatment for Ewing family of tumors in adults: the University of Florida experience. Int J Radiat Oncol Biol Phys. 2008 Nov 15; 72(4):11401145. [PubMed: 18513886]

91. Indelicato DJ, Keole SR, Shahlaee AH, et al. Impact of local management on long-term outcomes in Ewing tumors of the pelvis and sacral bones: the University of Florida experience. Int J Radiat Oncol Biol Phys. 2008 Sep 1; 72(1):41-48. [PubMed: 18234436]

92. Davis AM, O'Sullivan B, Turcotte R, et al. Late radiation morbidity following randomization to preoperative versus postoperative radiotherapy in extremity soft tissue sarcoma. Radiother Oncol. 2005 Apr; 75(1):48-53. [PubMed: 15948265]

93. Erkizan HV, Kong Y, Merchant M, et al. A small molecule blocking oncogenic protein EWS-FLI1 interaction with RNA helicase A inhibits growth of Ewing's sarcoma. Nat Med. 2009 Jul; 15(7): 750-756. [PubMed: 19584866]

94. Mateo-Lozano S, Tirado OM, Notario V. Rapamycin induces the fusion-type independent downregulation of the EWS/FLI-1 proteins and inhibits Ewing's sarcoma cell proliferation. Oncogene. 2003 Dec 18; 22(58):9282-9287. [PubMed: 14681687]

95. Hu-Lieskovan S, Heidel JD, Bartlett DW, Davis ME, Triche TJ. Sequence-specific knockdown of EWS-FLI1 by targeted, nonviral delivery of small interfering RNA inhibits tumor growth in a murine model of metastatic Ewing's sarcoma. Cancer Res. 2005 Oct 1; 65(19):8984-8992. [PubMed: 16204072]

96. Yee D, Favoni RE, Lebovic GS, et al. Insulin-like growth factor I expression by tumors of neuroectodermal origin with the $\mathrm{t}(11 ; 22)$ chromosomal translocation. A potential autocrine growth factor. J Clin Invest. 1990 Dec; 86(6):1806-1814. [PubMed: 2174908]

97. Benini S, Manara MC, Baldini N, et al. Inhibition of insulin-like growth factor I receptor increases the antitumor activity of doxorubicin and vincristine against Ewing's sarcoma cells. Clin Cancer Res. 2001 Jun; 7(6):1790-1797. [PubMed: 11410521]

98. Toretsky JA, Gorlick R. IGF-1R targeted treatment of sarcoma. Lancet Oncol. 2010 Feb; 11(2): 105-106. [PubMed: 20036195]

99. Buck E, Gokhale PC, Koujak S, et al. Compensatory insulin receptor (IR) activation on inhibition of insulin-like growth factor-1 receptor (IGF-1R): rationale for cotargeting IGF-1R and IR in cancer. Mol Cancer Ther. 2010 Oct; 9(10):2652-2664. [PubMed: 20924128]

100. Garofalo C, Manara MC, Nicoletti G, et al. Efficacy of and resistance to anti-IGF-1R therapies in Ewing's sarcoma is dependent on insulin receptor signaling. Oncogene. 2011 Jan 31.

101. Salazar R, Reidy-Lagunes D, Yao J. Potential synergies for combined targeted therapy in the treatment of neuroendocrine cancer. Drugs. 2011 May 7; 71(7):841-852. [PubMed: 21568362]

102. Ordonez JL, Osuna D, Herrero D, de Alava E, Madoz-Gurpide J. Advances in Ewing's sarcoma research: where are we now and what lies ahead? Cancer Res. 2009 Sep 15; 69(18):7140-7150. [PubMed: 19738075] 
103. Sohn HW, Choi EY, Kim SH, et al. Engagement of CD99 induces apoptosis through a calcineurin-independent pathway in Ewing's sarcoma cells. Am J Pathol. 1998 Dec; 153(6): 1937-1945. [PubMed: 9846983]

104. Scotlandi K, Baldini N, Cerisano V, et al. CD99 engagement: an effective therapeutic strategy for Ewing tumors. Cancer Res. 2000 Sep 15; 60(18):5134-5142. [PubMed: 11016640]

105. Rocchi A, Manara MC, Sciandra M, et al. CD99 inhibits neural differentiation of human Ewing sarcoma cells and thereby contributes to oncogenesis. J Clin Invest. 2010 Mar 1; 120(3):668680. [PubMed: 20197622]

106. Cho HM, Rosenblatt JD, Tolba K, et al. Delivery of NKG2D ligand using an anti-HER2 antibody-NKG2D ligand fusion protein results in an enhanced innate and adaptive antitumor response. Cancer Res. 2010 Dec 15; 70(24):10121-10130. [PubMed: 21159634] 


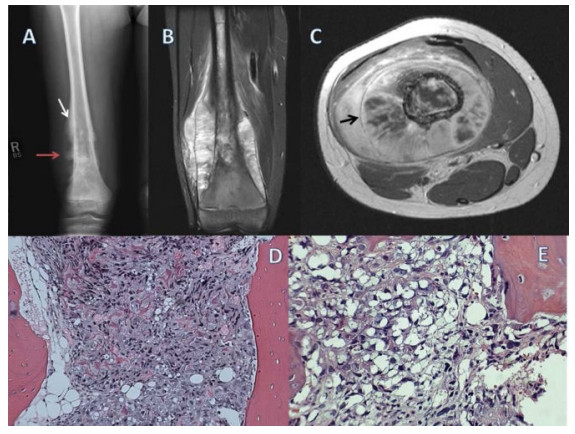

Figure 1.

A) Plain radiograph of the right femur in a skeletally immature patient shows a destructive, bone forming lesion that involves the entire metaphysis. Small white arrow designates a Codman's triangle, periosteal new bone formed in response to tumor. This is contrasted to the less organized malignant bone B) A coronal T2-weighted image shows a large soft-tissue mass with new bone formation and periosteal elevation. Note the intramedullary and extramedullary tumor extension. C) Axial T1 weighted images, used for surgical planning, show the nearby superficial femoral artery, vein, and sciatic nerve. Periosteal new bone is appreciated in a circumferential pattern around the femoral shaft as designated by the small black arrow. D) A low-power photomicrograph shows a highly cellular lesion with osteoid formation. E) Higher-power reveals densely staining chromatin and significant nuclear pleomorphism. 


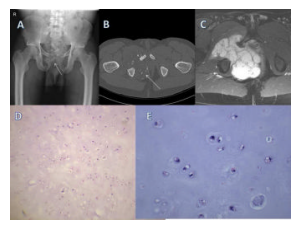

Figure 2.

A) An AP radiograph of a skeletally mature patient shows a large soft tissue mass in the right hemi-pelvis with punctate calcifications characteristic of cartilage (white arrow). B) Axial CT scan image shows the anterior and posterior extent of the tumor extension into surrounding soft tissue. Punctate or "stippled" calcifications are readily apparent. C) Axial T2 weighted MRI shows a large soft tissue mass arising from the bone that extends into the soft tissues. Proximity to neurovascular structures is demonstrated. Bright signal is indicative of high water content. D) Low powered photomicrograph shows relatively low cellularity and nuclear atypia. Abundant chondroid matrix is seen on hematoxylin and eosin staining. E) Higher power shows minimal cellular atypia and pleomorphism, most consistent with a low-grade chondrosarcoma. 


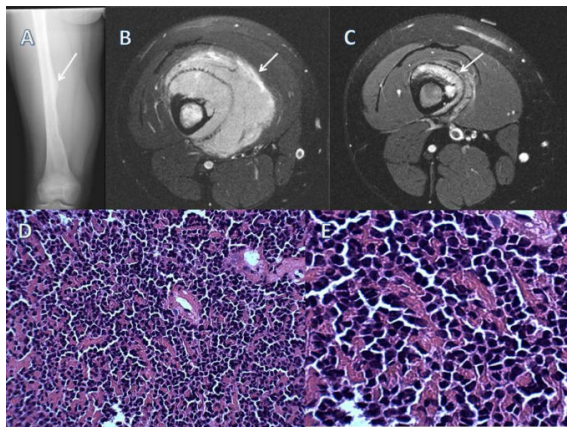

Figure 3.

A) An AP radiograph of a femoral Ewing's sarcoma showing a diaphyseal based lesion with an associated Codman's triangle (white arrow). B) Axial T2 weighted image prior to neoadjuvant therapy shows a large soft tissue mass with little bone destruction typical of Ewing's sarcoma.. C) Post chemotherapy axial T2 weighted image shows a significant decrease in the size of the soft tissue mass. White arrows designate the extent of soft tissue mass. D) A low powered photomicrograph shows a highly cellular neoplasm predominantly small-round blue cells. E) A higher power photomicrograph. 